\title{
ANALISIS RESIKO PROYEK PADA PEKERJAAN JEMBATAN SIDAMUKTI - KADU DI MAJALENGKA DENGAN METODE FMEA DAN DECISION TREE
}

\author{
Erni Sari \\ ${ }^{1)}$ Program Studi Magister Teknik Sipil, Sekolah Pasca Sarjana \\ Universitas Katholik Parahiyangan \\ Jl. Merdeka No.30 Bandung 40117 \\ email : ernisarihombing@yahoo.com \\ ${ }^{2)}$ Teknik Sipil, Fakultas Teknik, Universitas Majalengka \\ Jl. Universitas Majalengka No.01 Majalengka, email : \\ ernisarihombing@yahoo.com
}

\begin{abstract}
ABSTRAK
Jembatan tidak hanya sebagai alat penghubung lalulintas antar daerah atau antar pulau Jembatan juga sebagai alat untuk melancarkan roda ekonomi antar daerah satu dengan daerah lain yang teerhambat oleh suatu rintangan.

Pembangunan suatu jembatan tidak lepas dari resiko yang bersifat tidak pasti.Untuk mendakati ketidak pastian tersebut dapat di antisipasi melalui manajemen resiko. Oleh karna itu, perlu adanya analisa terhadap resiko pada proyek jembatan di lihat dari dampak (severity), kemungkinan terjadinya resiko (occurace), deteksi resiko (detektion) dan hasilnya yg berupa Risk Priority Number.

Untuk mengindentifikasi factor-factor resiko pembangunan jembatan Sidamukti- Kadu di Kabupaten Majalengka menggunakan Metode Failure Mode and Effect Analysis (FMEA) bersifat kuantitatif dan Metode Descision Tree bersifat kualitatif.

Dalam metode Failure Mode and Effect Analysis (FMEA) digunakan nilai resiko (NR) dan matriks resiko.Sedangkan metode Descision Tree(pohon keputusan) di gunakan untuk mendapatkan informasi untuk tujuan pengambilan sebuah keputusan.Dalam memilih alternatif keputusan digunakanlah dengan menghitung Expected Monetary Value (EMV).
\end{abstract}

Kata Kunci : Jembatan Sidamukti-Kadu, analisa resiko, Metode FMEA, Metode Decision Tree, EMV

\section{PENDAHULUAN}

1. Latar Belakang

Jembatan merupakan suatu konstruksi yang gunanya untuk meneruskan jalan melalui suatu rintangan yang berada lebih rendah, dimana rintangan ini biasanya jalan berupa lain yaitu jalan air atau jalan lalu lintas biasa (Struyk, 1995). Jembatan memiliki arti penting bagi setiap orang, dengan tingkat kepentingan yang berbedabeda tiap orangnya (Supriyadi, 2000). Menurut Dr. Ir. Bambang Supriyadi, jembatan bukan hanya konstruksi yang berfungsi menghubungkan suatu tempat ke tempat lain akibat terhalangnya suatu rintangan, namun jembatan merupakan suatu sistem transportasi. Jika jembatan runtuh maka sistem transportasi akan lumpuh.

Pembangunan suatu jembatan tidak lepas dari risiko yang bersifat tidak pasti.Untuk mendekati ketidakpastian tersebut dapat diantisipasi melalui manajemen risiko.

Dari tahap identifikasi dapat dilihat kemungkinan potensi risiko dari setiap aktifitas dan kemudian dianalisis besarnya probabilitas munculnya dan dampak dari biaya yang akan timbul terhadap kelangsungan proyek konstruksi. Oleh karena itu, perlu adanya analisa terhadap risiko apa saja yang akan terjadi dan seberapa besar dampak (severity), dan kemungkinan (probability) kejadian risiko tersebut terjadi agar dapat menentukan strategi mitigasi yang tepat untuk menangani risiko tersebut.

Berdasarkan hal tersebut di atas, maka saya mencoba mengidentifikasi faktor-faktor risiko pembangunan jembatan daerah pengunungan dimana analisa ini bersifat kuantitatif dengan 
menggunakan metode Failure Mode and effect Analysis (FMEA) dan bersifat kualitatif dengan mengunakan Descision Tree.

\section{Rumusan Masalah}

Bedasarkan latar belakang di atas, maka dalam menganalisis proyek jembatan menggunakan metode FMEA yang besrifat kuantitatif dan menggunakan metode Descision Tree yang bersifat kualitatif. Dengan mengindentifikasi resiko - resiko proyek dilihat dari seberapa besar dampak (Severity), kemungkinan terjadinya resiko (Occurace), deteksi resiko (Detection) dan hasilnya berupa

Riks Priority Number. Resiko apa saja yang terjadi pada setiap proses pelaksanaan proyek jembatan Sidamukti - Kadu di Kabupaten Majalengka.

\section{Maksud dan Tujuan}

Maksud penelitian ini adalah untuk menganalisis dampak resiko pada proyek jembatan Sidamukti - Kadu di Kabupaten Majalengka dengan menggunakan metode FMEA (Faelur Mode and Effect Analysis ). Dan metode Decision Tree sehingga di ketahui resiko yg keritis dari kegiatan tersebut.

Adapun tujuannya yakni untuk menganalisi resiko - resiko yang mungkin terjadi agar pelaksanaan pekerjaan proyek jembatan dapat berjalan dengan lancer, sehingga nantinya dapat di gunakan sebagai dasar dalam pengambilan keputusan penanganan jembatan Sidamukti Kadu di Kabupaten Majalengka.

\section{Batasan Masalah}

Untuk menghindari pembahasan masalah yang terlalu luas sehingga dapat merancukan tujuan pembahasan. Maka, sesuai dengan judul yang di ambil pada tugas besar manajemen resiko, akan di bahas mengenai analisis resiko proyek jembatan dengan menggunakan metodeFMEA dan Decision Tree dengan menghitung Expected monetary Value (EMV) dari kejadian resiko kritis dan pengambilan keputusan penanganan jembatan.

\section{LANDASAN TEORI \\ 1. Pengertian Jembatan}

Pembangunan jembatan Sidamukti - Kadu merupakan jembatan penghubung kedua Kabupaten yaitu Kabupaten Majalengka dan Kabupaten Sumedang. Jembatan ini merupakan jembatan yang sangat vital sebagai urat nadi transportasi baik untuk pelayanan masyarakat umum antara lain barang kebutuhan sehari-hari, jasa transportasi, pariwisata ke arah Bendungan Jatigede Kabupaten Sumedang.

Dengan rencana pengembangan agribisnis mangga gedong gincu dan industrialisasi perikanan pemerintah Kabupaten Majalengka berusaha memenuhi sarana dan infrastruktur di sekitar kawasan agribisnis dan perikanan yang ada di Desa Sidamukti untuk mempermudah akses mobilisasi.

Untuk menunjang hal tersebut maka salah satu kebutuhan infrastruktur yang dibutuhkan adalah pembangunan jembatan Sidamukti-Kadu yang berada pada ruas jalan Sidamukti - Kadu yang akan menjadi akses distribusi mangga gedong gincu dan perikanan dari Kabupaten Majalengka ke Kabupaten Sumedang.

Jembatan merupakan suatu konstruksi yang gunanya untuk meneruskan jalan melalui suatu rintangan yang berada lebih rendah. Rintangan ini biasanya jalan lain ( jalan alus atau jalan lalu lintas biasa ). Adanya jembatan, transportasi darat yang terputus oleh sungai ( floodway) dapat diatasi. Dikarenakan fungsinya yang penting maka jembatan harus dibuat kuat, yaitu mampu menerima beban di atasnya serta dapat digunakan dalam waktu yang lama.

Sejarah jembatan sudah cukup tua bersamaan dengan terjadinya hubungan komunikasi dan transportasi antara sesama manusia dan antara manusia dengan alam lingkungannya.Macam dan bentuk serta bahan yang digunakan mengalami perubahan sesuai dengan kemajuan jaman dan teknologi, mulai dari yang sederhana sekali sampai pada konstruksi yang mutakhir. 
Bagian-bagian dari konstruksi jembatan :

1. Superstrukture (Konstruksi bagian atas), struktur atas jembatan merupakan bagian yang menerima beban langsung yang meliputi berat sendiri, beban mati, beban mati tambahan, beban lalu lintas kendaraan, gaya rem, beban pejalan kaki.

2. Substrukture (konstruksi bagian bawah)

3. Foundation (Pondasi)

\section{Kriteria Perencanaan Jembatan}

Dalam perencanaan teknis jembatan perlu dilakukan identifikasi yang menyangkut beberapa hal antara lain: kondisi tata guna lahan, baik yang ada pada jalan pendukung maupun lokasi jembatan berkaitan dengan ketersediaan lahan yang ada. Kelas jembatan yang disesuaikan dengan kelas jalan dan volume lalu lintas.Struktur tanah, geologi dan topografi serta kondisi sungai dan perilakunya.

1. Pemilihan Lokasi Jembatan

Dasar utama penempatan jembatan sedapat mungkin tegak lurus terhadap sumbu rintangan yang dilalui, sependek, sepraktis dan sebaik mungkin untuk dibangun diatas jalur rintangan. Beberapa ketentuan dalam pemilihan lokasi jembatan dengan memperhatikan kondisi setempat dan ketersediaan lahan adalah sebagai berikut: Lokasi jembatan harus direncanakan sedemikian rupa sehingga tidak menghasilkan kebutuhan lahan yang besar sekali. Lahan yang dibutuhkan harus sedikit mungkin mengenai rumah penduduk sekitarnya, dan diusahakan mengikuti as jalan existing.

2. Bahan Konstruksi Jembatan

Ditinjau dari klasifikasi bangunan penyeberangan secara umum

3. Pemilihan Konstruksi Atas Jembatan

Pemilihan konstruksi atas jembatan ditetapkan dengan mempertimbangkan konstruksi yang kuat, aman, dan ekonomis. Hal yang perlu diperhatikan dalam memilih jenis konstruksi atas antara lain :

1. Mudah pelaksanaannya

2. Biaya pelaksanaan murah
3. Pengadaan bahan relatif muda

4. Biaya peralatan relatif rendah

5. Cukup kuat dengan biaya relatif murah

6. Bentang sungai

4. Pemilihan konstruksi bawah jembatan

harus memperhatikan kondisi tanah setempat dan pola aliran sungai. Konstruksi ditetapkan berdasarkan pertimbangan kekuatan, biaya, serta kemudahan dalam pelaksanaan. Tahapan yang harus dilakukan dalam perencanaan fondasi jembatan antara lain:

1. Pemeriksaan rencana tahanan lateral ultimit geser maupun tahanan tekanan pasif pada pondasi.

2. Stabilitas terhadap geser dan guling

3. Kapasitas daya dukung ultimit.

4. Penurunan (settlement) pada pondasi.

\section{Manajemen Risiko}

Risiko merupakan variasi dalam hal-hal yang mungkin terjadi secara alami didalam suatu situasi (Fisk, 1997).Risiko adalah ancaman terhadap kehidupan, properti atau keuntungan finansial akibat bahaya yang terjadi (Duffield \& Trigunarsyah, 1999).Secara umum risiko dikaitkan dengan kemungkinan (probabilitas) terjadinya peristiwa diluar yang diharapkan (Soeharto, 1995).

Jadi risiko adalah variasi dalam hal-hal yang mungkin terjadi secara alami atau kemungkinan terjadinya peristiwa diluar yang diharapkan yang merupakan ancaman terhadap properti dan keuntungan finansial akibat bahaya yang terjadi.

\section{Metodelogi Penelitian}

Dalam menganalisis resiko pekerjaan jembatan di gunakan metode FMEA dan metode Decision Tree.

\section{Metode Failure Mode and Effect Analysis (FMEA). \\ FMEA (Failure Mode and Effects Analysis)} pada awalnya dibuat oleh Aerospace Industry pada tahun 1960-an. FMEA mulai digunakan oleh Ford pada tahun 1980-an, AIAG 
(Automotive Industry Action Grup) dan American Society for Quality Control (ASQC) menetapkannya sebagai standar pada tahun 1993. Saat ini FMEA merupakan salah satu core tools dalam ISO/TS 16949:2022 (Techical Spesification for Automotive Industry).

FMEA adalah suatu prosedur terstruktur untuk mengidentifikasi dan mencegah sebanyak mungkin mode kegagalan (failure mode). Suatu mode kegagalan adalah apa saja yang termasuk dalam kecacatan, kondisi diluar spesifikasi yang ditetapkan, atau perubahan dalam produk yang menyebabkan terganggunya fungsi dari produk (Gasperz, 2002).

Terdapat banyak variasi didalam rincian failure modes and effect analysis (FMEA), tetapi semua itu memiliki tujuan untuk mencapai :

1. Mengenal dan memprediksi potensial kegagalan dari produk atau proses yang dapat terjadi.

2. Memprediksi dan mengevalusi pengaruh dari kegagalan pada fungsi dalam sistem yang ada.

3. Menunjukkan prioritas terhadap perbaikan suatu proses atau sub sistem melalui daftar peningkatan proses atau sub sistem yang harus diperbaiki

4. Mengidentifikasi dan membangun tindakan perbaikan yang bisa diambil untuk mencegah atau mengurangi kesempatan terjadinya potensikegagalan atau pengaruh pada sistem.

5. Mendokumentasikan proses secara keseluruan.

Untuk menentukan prioritas dari suatu bentuk kegagalan maka tim FMEA harus mendefinisikan terlebih dahulu tentang Severity, Occurrence, Detection, serta hasil akhirnya yang berupa Risk Priority Number.

\section{Severity}

Severity adalah langkah pertama untuk menganalisa resiko yaitu menghitung seberapa besar dampak/intensitas kejadian mempengaruhi output proses. Dampak tersebut diranking mulai skala 1 sampai 10 , dimana 10 merupakan dampak terburuk. Adapun kriteria penilaian severity adalah sebagai berikut :

\begin{tabular}{|c|c|c|}
\hline Rangking & Akibat/Efek & Kriteria verbal \\
\hline 1 & Tidak ada akibat & $\begin{array}{l}\text { Tidak mengakibatkan apa-apa, tidak memerlukan } \\
\text { penyesuaian }\end{array}$ \\
\hline 2 & $\begin{array}{l}\text { Akibat sangat } \\
\text { ringan }\end{array}$ & Pengujian tetap berjalan, hanya sedikit gangguan \\
\hline 3 & Akibat ringan & $\begin{array}{l}\text { Pengujian dapat terus dilaksanakan namun ada penurunan } \\
\text { performa alat }\end{array}$ \\
\hline 4 & Akibat minor & $\begin{array}{l}\text { Pengujian dapat dilaksanakan, namun ada penurunan } \\
\text { performa yang signifikan }\end{array}$ \\
\hline 5 & Akibat moderat & $\begin{array}{c}\text { Pengujian tidak dapat berjalan normal dengan atau tanpa } \\
\text { kerusakan }\end{array}$ \\
\hline 6 & Akibat signifikan & $\begin{array}{c}\text { Pengujian tidak dapat dilaksanakan karena sedikit } \\
\text { kerusakan }\end{array}$ \\
\hline 7 & Akibat major & $\begin{array}{l}\text { Pengujian tidak dapat dilaksanakan karena kerusakan } \\
\text { yang cukup parah pada peralatan }\end{array}$ \\
\hline 8 & Akibat ekstrem & $\begin{array}{l}\text { Pengujian tidak dapat dilaksanakan karena kerusakan } \\
\text { yang sangat parah }\end{array}$ \\
\hline 9 & Akibat serius & $\begin{array}{c}\text { Pengujian gagal dilaksanakan dengan kerusakan yang } \\
\text { berdampak pada sistem alat namun masih ada peringatan }\end{array}$ \\
\hline 10 & Akibat berbahaya & $\begin{array}{l}\text { Pengujian gagal dilaksanakan dengan kerusakan yang } \\
\text { berdampak pada sistem alat tanpa ada peringatan }\end{array}$ \\
\hline
\end{tabular}

2. Occurrence

Occurrence adalah kemungkinan bahwa penyebab tersebut akan terjadi dan menghasilkan bentuk kegagalan selama masa penggunaan produk. Dengan memperkirakan kemungkinan occurrencepada skala 1 sampai 10.Adapun kriteria penilaian occurrence adalah sebagai berikut:

Tabel 2. Kriteria Kemungkinan Terjadinya Resiko (Occurace)
\begin{tabular}{|c|l|l|l|}
\hline Rangking & \multicolumn{1}{|c|}{ Kejadian } & \multicolumn{1}{|c|}{ Kriteria verbal } & Tingkat terjadinya kegagalan \\
\hline 1 & $\begin{array}{l}\text { Hampir tidak } \\
\text { pernah }\end{array}$ & Risiko hampir tidak pernah terjadi & Probablitias terjadinya 0 - 1 \\
\hline 2 & Remote & Risiko jarang terjadi & Probablitias terjadinya $>1$ - 2 \\
\hline 3 & Sangat sedilit & Risiko yang terjadi sangat sedilit & Probablitias terjadinya $>2-3$ \\
\hline 4 & Sedikit & Risiko yang terjadi sedilit & Probablitias terjadinya $>3-4$ \\
\hline 5 & Rendah & Risiko yang terjadi pada tinggkat rendah & Probablitias terjadinya $>4-5$ \\
\hline 6 & Medium & Risiko yang terjadi pada tingkat medium & Probablitias terjadinya $>5-6$ \\
\hline 7 & Agak tinggi & Risiko yang terjadi agak tinggi & Probablitias terjadinya $>6-7$ \\
\hline 8 & Tinggi & Risiko yang terjadi tinggi & Probablitias terjadinya $>7-8$ \\
\hline 9 & Sangat tinggi & Risiko yang terjadi sangat tinggi & Probablitias terjadinya $>8-9$ \\
\hline 10 & Hampir selalu & Risiko selalu terjadi & Probablitias terjadinya $>9$ \\
\hline
\end{tabular}

\section{Detection}

Nilai Detectiondiasosiasikan dengan pengendalian saat ini.Detectionadalah pengukuran terhadap kemampuan mengendalikan / mengontrol kegagalan yang dapat terjadi. Adapun kriteria penilaian detection adalah sebagai berikut : 
Tabel 3. Kriteria Deteksi Resiko (Detection)

\begin{tabular}{|c|l|l|}
\hline Rangking & \multicolumn{1}{|c|}{ Akibat } & \multicolumn{1}{c|}{ Kriteria } \\
\hline 1 & Hampir pasti & Pasti terdeteksi \\
\hline 2 & Sangat tinggi & Sangat mudah terdeteksi \\
\hline 3 & Tinggi & Mudah terdeteksi \\
\hline 4 & Moderately high & Dapat terdeteksi \\
\hline 5 & Moderate & Cukup Mudah terdeteksi \\
\hline 6 & Rendah & Relatif jarang terdeteksi \\
\hline 7 & Sangat rendah & Sangat jarang terdeteksi \\
\hline 8 & Remote & Relatif sulit terdeteksi \\
\hline 9 & Very remote & Sulit terdeteksi \\
\hline 10 & Tidak pasti & Tidak dapat terdeteksi \\
\hline
\end{tabular}

1. Fungsi proses berisi deskripsi singkat mengenai proses dan dianalisa risikonya.

2. Moda kegagalan merupakan suatu kemungkinan hambatan yang dapat terjadi dalam proses persiapanan maupun pelaksanaan.

3. Mendaftarkan efek kegagalan terhadap setaip modus kegagalan.

4. Menetapkan bobot keparahan $(\mathrm{S}=$ saverity) untuk setiap kegagalan.

5. Menetapkan bobot keterjadian $(\mathrm{O}=$ occurance) atau sesering apa penyebab kejadian untuk setiap modus kegagalan.

6. Menetapkan bobot deteksi $(\mathrm{D}=$ detection $)$ untuk setiap modus kegagalan/efek kegagalan.

7. Menghitung nilai RPN (Risk Priority Number).

$$
\mathrm{RPN}=\mathrm{S} \times \mathrm{O} \text { I }
$$

$$
\begin{array}{r}
\text { Dimana: } \quad \mathrm{S}=\text { Severity } \\
\mathrm{O}=\text { Occurance } \\
\mathrm{D}=\text { Detectability }
\end{array}
$$

8. Memprioritaskan modus kegagalan yang memiliki nilai RPN tertinggi.

9. Mengambil tindakan untuk mengeliminasi atau mengurangi modus kegagalan yang mempunyai risiko tertinggi.

10. Menghitung kembali nilai RPN setelah modus kegagalan telah dikurangi atau dieleminasi.

\section{a. Nilai Resiko (NR)}

Nilai RPN dari FMEA tidak valid untuk digunakan dalam analisa kualitatif, karena nilai detection dapat mengaburkan kritis atau tidaknya suatu risiko.Fungsi dari RPN dalam FMEA secara umum untuk menentukan potensi risiko yang sulit untuk dideteksi agar dapat lebih diprioritaskan dan ditangani.

Nilai rating hasil dari FMEA dihitung dengan severity dan occurency tanpa menyertakan nilai detection.Hasil pemeringkatan nilai RPN dan nilai risiko (NR). Hasil Nilai Risiko (NR) menggunan rumus sebagai berikut:

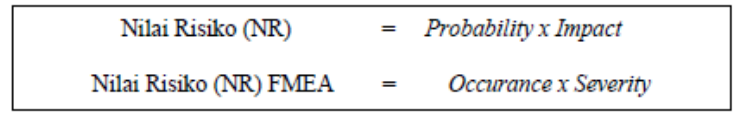

\section{b. Matrix Resiko}

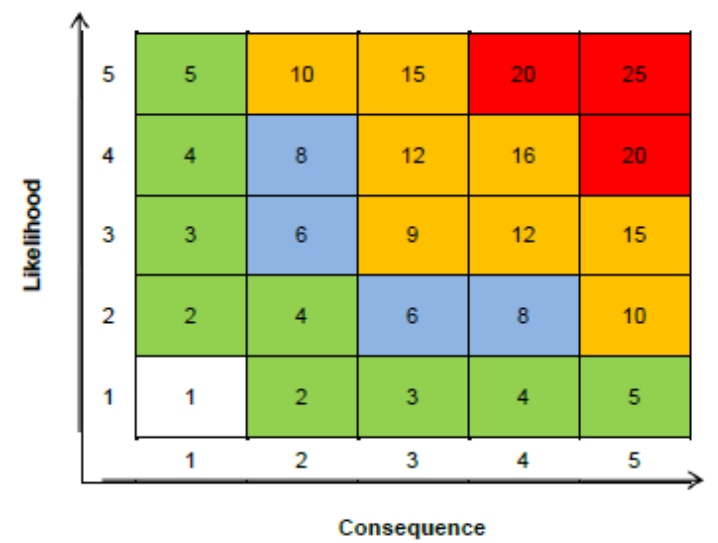

Tabel. 4 Rating Risiko

\begin{tabular}{|c|c|}
\hline \multicolumn{2}{|c|}{ Risk Significant Rankings } \\
\hline Consequence $\times$ Likelihood & Significance \\
\hline$>16$ & Kritis \\
\hline $9-16$ & Tinggi \\
\hline $6-8$ & Sedang \\
\hline $2-5$ & Rendah \\
\hline$<2$ & Diabaikan \\
\hline
\end{tabular}

2. Metode Decision Tree (Pohon Keputusan)

Pohon keputusan adalah sebuah flowchart seperti struktur tree, dimana tiap internal node 
menunjukkan sebuah test pada sebuah atribut, setiap cabang menunjukkan hasil dari test, dan leaf node menunjukkan kelas (Sujana, 2010).

Pohon keputusan biasanya digunakan untuk mendapatkan informasi untuk tujuan pengambilan sebuah keputusan. Pohon keputusan dimulai dengan sebuah root node (titik awal) yang diapakai oleh user untuk mengambil tindakan. Dari node root ini, user memecahkan sesuai dengan algoritma decision tree.

Hasil akhirnya adalah sebuah pohon keputusan dengan setiap cabangnya menunjukkan kemungkinan skenario dari keputusan yang diambil serta hasilnya.

Manfaat utama dari penggunaan pohon keputusan adalah kemampuannya untuk membreak down proses pengambilan keputusan yang kompleks menjadi lebih simpel sehingga pengambil keputusan akan lebih menginterpretasikan solusi dari permasalahan.

Prosedur untuk melakukan analisis pohon keputusan adalah sebagai berikut :

1. Membuat diagram pohon (Tree Diagraming)

> Identifikasi semua titik keputusan dan kemungkinan lain yang akan terjadi.

$>$ Identifikasi alternatif keputusan untuk setiap titik keputusan.

$>$ Identifikasi apa yang mungkin terjadi dari setiap keputusan yang diambil.

$>$ Membuat sebuah diagram pohon yang menunjukkan urutan keputusan dan kejadian yang mungkin terjadi.

2. Estimasi kemungkinan $($ Expected $\operatorname{cost}=\mathrm{EC})$

$>$ Estimasi kemungkinan hasil yang akan diperoleh dari berbagai kejadian yang mungkin terjadi.

$>$ Estimasi konsekuensi keuangan dari setiap hasil yang mungkin dari berbagai alternatif keputusan.

3. Evaluasi dan seleksi

$>$ Perhitungkan nilai yang diharapkan dari setiap alternatif keputusan.
$>$ Pilih alternatif keputusan yang menawarkan nilai yang diharapkan yang paling optimal.

\section{Expected Monetary Value (EMV)}

Expected Monetary Value atau perkiraan nilai moneter adalah suatu kriteria yang memanfaatkan probabilitas tentag terjadinya situasi masa depan dalam pemilihan alternatifalternatif keputusan. Rumus untuk mencari Expected Monetary Value (EMV) adalah sebagai berikut :

$$
E M V=\sum_{n=1}^{N} \text { Value }_{n} \times \text { Probability }_{n}
$$

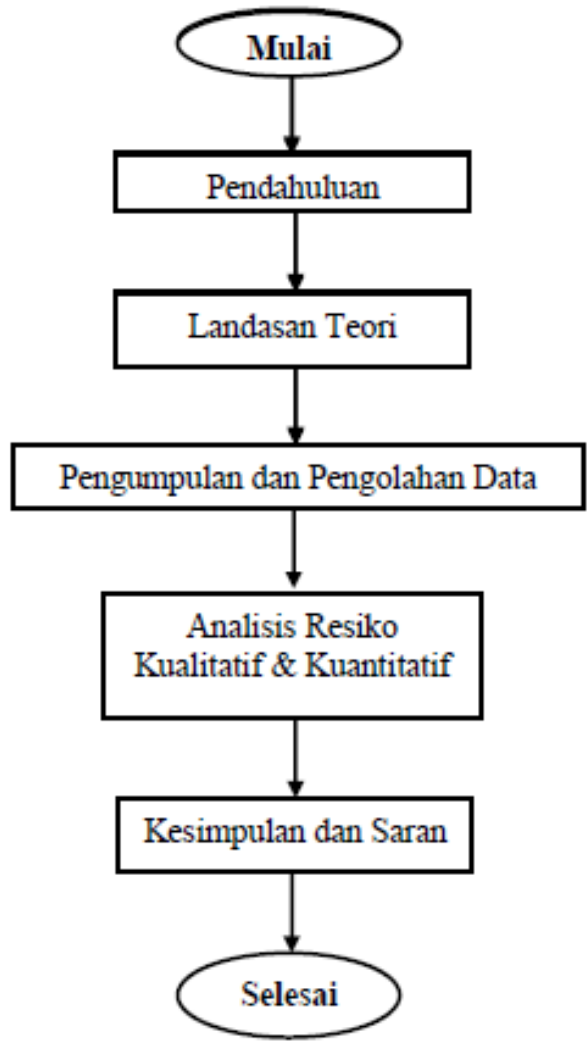

Gambar 1.Flowchart Penelitian

\section{Analisis Perhitungan Risiko Pekerjaan Jembatan}

\section{Lokasi Jembatan}

Lokasi penelitian ini berjarak 7,3 $\mathrm{Km}$ dari kampus Teknik Universitas Majalengka dari proyek pembangunan jembatan Sidamukti - 
Kadu terletak di Dusun Ciande, Desa Sidamukti, Kecamatan Majalengka, Kabupaten Majalengka tepatnya di Kali Cilutung perbatasan dengan Desa Kadu, Kecamatan Jatigede, Kabupaten Sumedang.

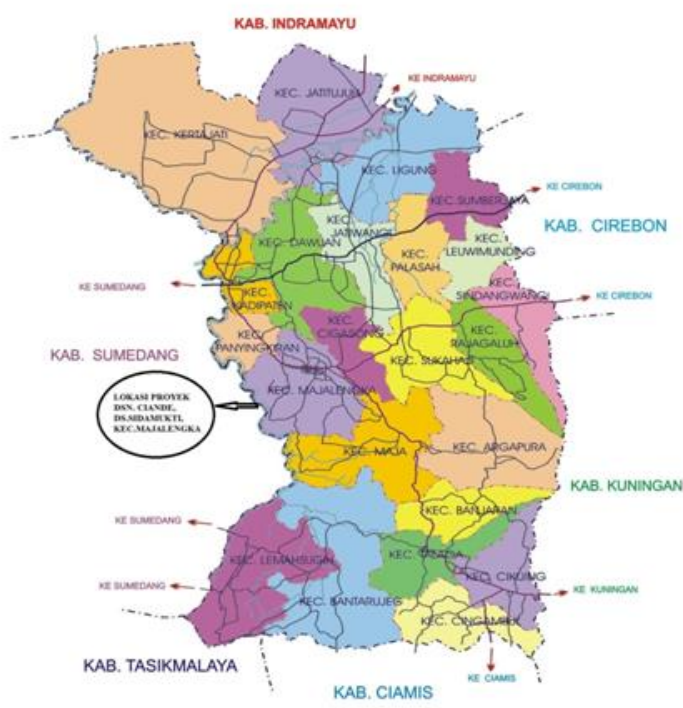

Gambar 2.Lokasi Proyek Pembangunan Jembatan Sidamukti-Kadu

\section{Pengolahan Data}

a. Identifikasi Resiko dengan menggunakan metode FMEA

Langkah awal dalam identifikasi risiko dengan menggunakan metode FMEA adalah membuat daftar failure/kegagalan dari masingmasing proses pekerjaan. Hal ini dilakukan untuk mengetahui risikorisiko yang relevan dengan proyek pembangunan jembatan kayu di daerah pegunungan Kab.Pinrang (Studi kasus pembangunan jembatan kayu desa makula kec. Lembang), sehingga setelah risiko teridentifikasi, maka akan didapatkan nilai occurance, severity dan detection untuk setiap risiko.
Tabel 5 Nilai occurance, saverity, detection dan RPN untuk tiap risiko

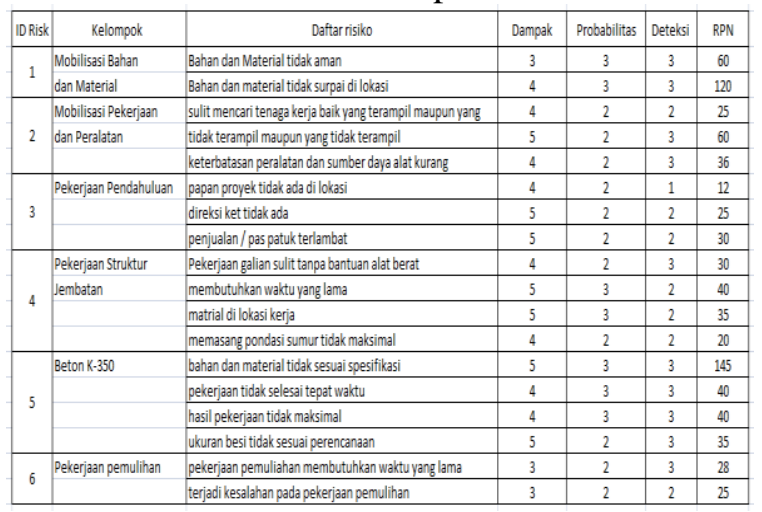

Berdasarkan risiko yang telah terdaftar dan diketahui nilai RPN masing-masing, maka dapat ditentukan risiko yang masuk dalam kategori kritis. Risiko kritis tersebut akan dianalisis lebih lanjut sebagai langkah awal dari tindakan penanganan risiko yang lebih baik. Suatu risiko dikategorikan sebagai risiko kritis jika memiliki nilai RPN di atas nilai kritis.Nilai kritis RPN ditentukan dari rata-rata nilai RPN dari seluruh risiko.

$$
\begin{aligned}
\text { nilai } \text { kritis }= & \frac{\text { total } R P N}{\text { jumlah daftar resiko }} \\
& =30
\end{aligned}
$$

Berdasarkan perhitungan nilai kritis RPN maka diperoleh 15 (lima belas) risiko kritis pada tahap mobilisasi bahan dan material dan, tahap pekerjaan struktur jembatan dengan nilai RPN berada di atas 30,00. Maka daftar resiko yang memiliki nilai $\mathrm{RPN} \geq 30,00$ masuk sebagai kategori resiko serius. Berikut tabel daftar risiko serius:

Dari daftar resiko serius diatas, penilaian terhadap nilai RPN (yang selanjutnya menjadi PRPN) perlu ditinjau ulang, mengingat telah dilakukannya tindakan perbaikan sehingga nilai Severity, Occurance dan Detection tentu akan mengalami penurunan sebagai berikut:

$$
\begin{aligned}
& \text { nilai } \text { kritis }=\frac{\text { total } R P N}{\text { jumlah daftar resiko }}=\frac{200}{16} \\
& =12,5
\end{aligned}
$$


Sedangkan nilai kritis PRPN yang didapat dari hasil penelitian, yaitu 12,5. Maka yang masih masuk kedalam kategori resiko serius bahkan setelah dilakukannya tindakan perbaikan daftar resiko ialah yang memiliki nilai PRPN $\geq$ 12,5 yang dapat dilihat pada tabel dibawah. Dari daftar resiko serius tersebut selanjutnya dijadikan sebagai bahan analisa kuantitatif agar dapat diketahui pilihan mana yang memiliki resiko lebih tinggi dalam mengalami kerugian.

Diketahui bahwa risiko yang besar terjadi pada pekerjaan struktur jembatan, dimana yang paling memiliki risiko tinggi adalah pada pekerjaan struktur beton K 350.Oleh karena itu, perlu dilakukan penjadwalan kembali sebelum memulai pekerjaan agar mutu bahan dan material sesuai spesifikasi atau persyaratan.

\section{- Perhitungan Nilai Risiko (NR)}

Nilai RPN dari FMEA tidak valid untuk digunakan dalam analisa kualitatif, karena nilai detection dapat mengaburkan kritis atau tidaknya suatu risiko.Fungsi dari RPN dalam FMEA secara umum untuk menentukan potensi risiko yang sulit untuk dideteksi agar dapat lebih diprioritaskan dan ditangani.

Nilai rating hasil dari FMEA dihitung dengan severity dan occurency tanpa menyertakan nilai detection. Hasil pemeringkatan nilai RPN dan nilai risiko (NR) dari pembangunan jembatan dapat dilihat pada tabel dibawah :

Tabel 6. Nilai Rating hasil FMEA

\begin{tabular}{|c|c|c|c|c|c|}
\hline № & Potensial Failure Mode & Potential Failur Effect & Potential Causes & RPN & NR \\
\hline \multirow{2}{*}{1} & bahan dan material tidak & kualitatif mutu pekerjaan tidak & hujan sering terjadi & \multirow{2}{*}{45} & \multirow{2}{*}{15} \\
\hline & sesuai spesifikasi & bagus & sepanjang hari & & \\
\hline \multirow{2}{*}{2} & pekerjaan bekisting tidak & jadwal pelaksanaan & hujan & \multirow{2}{*}{30} & \multirow{2}{*}{15} \\
\hline & maksimal & terlamabat & & & \\
\hline 3 & material dilokasi kurang & jadawal pelaksanaan terlambat & stok material terbatas & 30 & 15 \\
\hline 4 & hasil pekerjaan tidak maksimal & kualitas pekerjaan tidak bagus & tenaga kurang berkualitas & 36 & 12 \\
\hline \multirow{2}{*}{5} & memasang pondasi tidak sesuai & kualitas pekerjaan tidak bagus & pekerjaan tidak & \multirow{2}{*}{36} & \multirow{2}{*}{12} \\
\hline & perencanaan & tidak baik & maksimal & & \\
\hline \multirow{2}{*}{6} & ukuran besi tidak sesuai & hasil pekerjaan tidak & pekerjaan tidak & \multirow{2}{*}{30} & \multirow{2}{*}{10} \\
\hline & perencanaan & bermutu & maksimal & & \\
\hline
\end{tabular}

- Matrix Risiko

Dari hasil analisa menggunakan metode FMEA diperoleh nilai risiko (NR) tertinggi bernilai 15 , pada tabel.4 risk rating masuk pada rating risko tinggi dan perlu dilakukan tindakan penanganan.

\section{b. Analisa Kuantitatif dengan Pohon Keputusan (Decision Tree)}

Untuk dapat menganalisa risiko secara kuantitatif, maka penulis menggunakan metode "decision tree" atau pohon keputusan sebagai analisanya. Daftar risiko yang akan dianalisa secara kuantitatif merupakan risiko dengan kriteria serius bahkan setelah dilakukan tindakan perbaikan yaitu terdapat pada pekerjaan struktur jembatan beton K350. Risiko yang mungkin terjadi yaitu bahan dan material tidak sesuai spesifikasi.Dan efek yang berkelanjutan bisa ditimbulkan dari risiko tersebut yaitu kualitas mutu pekerjaan tidak bagus.

Biaya pembangunan jembatan adalah sebesar Rp. 1.183.533.266,-. Untuk melaksanakan pekerjaan tahap pembangunan struktur jembatan K 350 memerlukan biaya pekerja perharinya sebesar Rp. 950.000,-dengan biaya peralatan sebesar Rp. 600.000,-. Dari data historis peluang terjadinya hujan adalah pada bulan Mei sebesar $50 \%$, bulan Juni sebesar $40 \%$ dan bulan Juli sebesar $30 \%$. Jika peluang terjadix hujan pada bulan mei, juni dan juli saat pekerjaan struktur beton dilaksanakan maka dapat menyebabkan turunnya kualitas mutu beton sehingga menyebabkan kualitas pekerjaan tidak bagus.

Dari data diatas dapat dibuat dengan menggunakan decision tree untuk mendapatkan alternatif terbaik untuk memulai pekerjaan struktur jembatan agar mutu beton tercapai. 


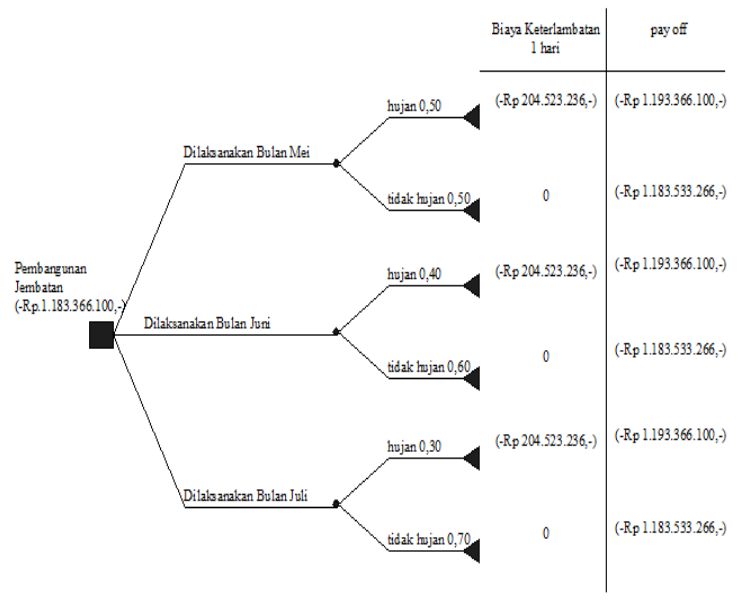

a. EMV bulan mei $=(0,50 \times(-\operatorname{Rp} .1 .193 .366 .100,-))+(0,50 \times(-\operatorname{Rp} .183 .533 .266))$

$=-\operatorname{Rp} \cdot 190.722 .091-\mathrm{Rp} 591.766 .633,-=1.188 .449 .683,-$

b. EMV bulan juni $=(0,40 \times(-\operatorname{Rp} \cdot 1.93 .366 .100))+(0,60 \times(-\operatorname{Rp} \cdot 1.183 .533 .266))$

$=-\operatorname{Rp} \cdot 477.346 .440,-+\operatorname{Rp} \cdot 7 \cdot 101 \cdot 199 \cdot 596,-=\operatorname{Rp} \cdot 1 \cdot 187.466 .400,-$

c. EMV bulan juli $=(0,30 \times(-R p \cdot 1.193 .366 .100))+(0,70 \times(-R p \cdot 1.183 .533 .266))$

$=-R p \cdot 358.009 .830,-+R p \cdot 8.284 .732 .862,-=R p \cdot 1.186 .483 .116,-$

Berdasarkan hasil analisa dengan menggunakan Metode Decision Tree terlihat jelas bahwa jika pekerjaan struktur beton K350 dilaksanakan pada bulan mei dan juni akan mengakibatkan kerugian dari segi mutu dan biaya. Maka sebaiknya kita melaksanakan pekerjaan struktur pada bulan juli karena peluang hujan lebih sedikit.Sehingga dampak risiko bisa diminimalisir pada bulan tersebut.

\section{KESIMPULAN DAN SARAN}

\section{Kesimpulan}

Berdasarkan hasil pengolahan data dan analisis, maka penulis mengambil beberapa kesimpulan sebagai berikut:

a. Hasil dari analisis kualitatif dengan metode FMEA menghasilkan nilai RPN sebesar 30,00 didapat 16 daftar resiko yang masuk sebagai kategori resiko serius. Setelah dilakukannya tindakan perbaikan nilai RPN mengalami penurunan menjadi PRPN sebesar 12,5 sehingga didapat 6 daftar resiko kritis, dan nilai risiko (NR) tertinggi bernilai 15 masuk pada rating risko tinggi dan perlu dilakukan tindakan penanganan.

b. Berdasarkan hasil analisa dengan menggunakan Metode Decision Tree maka pekerjaan struktur beton K350 sebaiknya dilaksanakan pada bulan juli karena memiliki nilai EMV lebih tinggi. Sehingga risiko akibat hujan dapat dikurangi dan berdampak pada penghematan biaya serta kualitas mutu beton dapat tercapai.

\section{Saran}

1. Melakukan pencatatan data historis pada tiap paket pekerjaan.

2. Dibutuhkan identifikasi risiko pada tiap pelaksanaan kegiatan sehingga dapat menghindari risiko pekerjaan.

3. Perlu dilakukan penanganan risiko pada tiap paket pekerja.

\section{DAFTAR PUSTAKA}

Asiyanto. 2005. Manajemen Produksi Untuk Jasa Konstruksi, Pradnya Paramita, Jakarta.

Soeharto, Iman. 2001. Manajemen Proyek (Dari konseptual sampai operasional) Jilid 2. Erlangga, Jakarta.

Sutadi, D.M.A. 2004. Analisa Perbandingan Risiko Kontrak Unit Price dan Kontrak Lumpsum dengan Metode Decision Tree (Tugas Akhir), Jurusan Teknik Sipil Fakultas Teknik Universitas Udayana, Jimbaran

Wahyuni, Putu Sukma. 2008. Analisis Perbandingan Risiko Biaya Antara Kontrak Lumpsum Dengan Kontrak Unit Price Menggunakan Metode Decision Tree. Jurnal Ilmiah Teknik Sipil, Fakultas Teknik, Universitas Udayana, Denpasar. 